\title{
Non-alcoholic Korsakoff syndrome in psychiatric patients with a history of undiagnosed Wernicke's encephalopathy
}

\section{Nikolakaros, Georgios}

2016-11-15

Nikolakaros , G , llonen , T , Kurki , T , Paju , J , Papageorgiou , S G \& Vataja , R 2016 , '

Non-alcoholic Korsakoff syndrome in psychiatric patients with a history of undiagnosed

Wernicke's encephalopathy ' , Journal of the Neurological Sciences , vol. 370 , pp. 296-302 . https://doi.org/10.1016/

http://hdl.handle.net/10138/229299

https://doi.org/10.1016/j.jns.2016.09.025

publishedVersion

Downloaded from Helda, University of Helsinki institutional repository.

This is an electronic reprint of the original article.

This reprint may differ from the original in pagination and typographic detail.

Please cite the original version. 


\title{
Non-alcoholic Korsakoff syndrome in psychiatric patients with a history of undiagnosed Wernicke's encephalopathy
}

\author{
Georgios Nikolakaros, MD ${ }^{\mathrm{a}, \mathrm{b}, *}$, Tuula Ilonen, $\mathrm{PhD}^{\mathrm{c}}$, Timo Kurki, MD, PhD ${ }^{\mathrm{d}, \mathrm{e}}$, Janina Paju, MSc ${ }^{\mathrm{c}}$, \\ Sokratis G. Papageorgiou, $\mathrm{MD}, \mathrm{PhD}^{\mathrm{f}}$, Risto Vataja, $\mathrm{MD}, \mathrm{PhD}^{\mathrm{g}}$ \\ a "Specialists in Psychiatry" Medical Center, Yliopistonkatu 33C28, 20100 Turku, Finland \\ b Satakunta Hospital District, Psychiatric Care Division, General Psychiatry Outpatient Clinic, Sairaalantie 3, 28500 Pori, Finland \\ ' Department of Psychiatry, University of Turku, Kunnallissairaalantie 20, rak. 9, 20700 Turku, Finland \\ d Terveystalo Pulssi Medical Center, Humalistonkatu 9-11, 20100 Turku, Finland \\ e Department of Radiology, University of Turku, Kiinamyllynkatu 4-8, 20520, Turku, Finland \\ ${ }^{\mathrm{f}}$ Cognitive Disorders/Dementia Unit, 2nd University Department of Neurology, Medical School, National and Kapodistrian University of Athens, University General Hospital "ATTIKON”, Rimini \\ street, 12462 Athens, Greece \\ ${ }^{\mathrm{g}}$ Division of Neuropsychiatry, Helsinki University Hospital, PL 100, 00029 HUS, Helsinki, Finland
}

\section{A R T I C L E I N F O}

\section{Article history:}

Received 21 July 2016

Received in revised form 30 August 2016

Accepted 14 September 2016

Available online 15 September 2016

\section{Keywords:}

Diffusion tensor imaging

Korsakoff syndrome

Neuropsychological tests

Positron-emission tomography

Psychiatric treatment

Wernicke's encephalopathy

\begin{abstract}
A B S T R A C T
Wernicke's encephalopathy is often undiagnosed, particularly in non-alcoholics. There are very few reports of non-alcoholic patients diagnosed with Korsakoff syndrome in the absence of a prior diagnosis of Wernicke's encephalopathy and no studies of diffusion tensor imaging in non-alcoholic Korsakoff syndrome. We report on three non-alcoholic psychiatric patients (all women) with long-term non-progressive memory impairment that developed after malnutrition accompanied by at least one of the three Wernicke's encephalopathy manifestations: ocular abnormalities, ataxia or unsteadiness, and an altered mental state or mild memory impairment. In neuropsychological examination, all patients had memory impairment, including intrusions. One patient had mild cerebellar vermis atrophy in MRI taken after the second episode of Wernicke's encephalopathy. The same patient had mild hypometabolism in the lateral cortex of the temporal lobes. Another patient had mild symmetrical atrophy and hypometabolism of the superior frontal lobes. Two patients were examined with diffusion tensor imaging. Reduced fractional anisotropy values were found in the corona radiata in two patients, and the uncinate fasciculus and the inferior longitudinal fasciculus in one patient. Our results suggest that non-alcoholic Korsakoff syndrome is underdiagnosed. Psychiatric patients with long-term memory impairment may have Korsakoff syndrome and, therefore, they should be evaluated for a history of previously undiagnosed Wernicke's encephalopathy.
\end{abstract}

(c) 2016 Elsevier B.V. All rights reserved.

\section{Introduction}

Korsakoff syndrome (KS) is characterized by chronic cognitive impairment that predominantly affects memory [1]. KS is caused by thiamine deficiency that often manifests as Wernicke's encephalopathy (WE) [2-5]. Alcohol abuse predisposes to thiamine deficiency; however, WE can also occur in malnourished non-alcoholics [5]. The full classic triad (ocular abnormalities, ataxia or unsteadiness, and an altered mental state or mild memory impairment) has been shown not to be a valid

\footnotetext{
* Corresponding author at: "Specialists in Psychiatry” Medical Center, Yliopistonkatu 33C28, 20100 Turku, Finland.

E-mail addresses: georgios.nikolakaros@utu.fi (G. Nikolakaros), tuula.ilonen@utu.fi (T. Ilonen), timo.kurki@terveystalo.com (T. Kurki), janina.paju@utu.fi (J. Paju), sokpapa@med.uoa.gr (S.G. Papageorgiou), risto.vataja@hus.fi (R. Vataja).
}

diagnostic tool, and instead, the operationalized criteria proposed by Caine et al (any two of four signs, the classic triad and dietary deficiency) are used to diagnose WE [5-7].

Previously, it was thought that non-alcoholic WE very rarely causes KS [8-10]. However, recent studies have shown that KS often follows non-alcoholic WE $[4,7,11]$. Still, results of a neuropsychological examination have been reported for only ten cases [12-20]. There are no diffusion tensor imaging (DTI) studies.

At least 94\% of non-alcoholic WEs remain undiagnosed [5]. It is conceivable that undiagnosed non-alcoholic WE is particularly prone to cause KS, but the recent literature contains only three case reports [12, $13,19]$. It has been suggested that patients with KS who have no recognized history of WE may come to the attention of psychiatrists [1]. Here we report on three psychiatric patients with KS likely related to undiagnosed non-alcoholic WE. 


\section{Cases}

All patients were identified between 2009 and 2013 by one of the authors (GN) by screening psychiatric patients with memory impairment for nutritional deficiency in history, prompted by the identification of Patient 1 . We reviewed medical records from other settings. All patients had undergone neurological assessment for their memory complaints; organic etiology was excluded but KS was not considered, and a psychiatric etiology for the memory impairment was suggested. The reports of previous neuropsychological examinations were available but not the numerical results.

Table 1 summarizes the manifestations of WE as assessed through history taking and a review of the medical records. All patients have memory problems that were first noticed during WE or soon after it. Psychiatric diagnoses were made in standard clinical care and were based on ICD-10 criteria. All patients have used alcohol only occasionally. None had a history of head trauma associated with unconsciousness or posttraumatic amnesia. All patients gave written permission for use of their medical information in this publication.

\subsection{Patient 1}

This female patient was referred at the age of 41 by the Unemployment officials for a psychiatric evaluation and has been treated by GN since that time.

\subsubsection{WE and memory impairment}

The patient had hyperemesis gravidarum and WE manifestations at the ages of 28 and 31 (Table 1). Memory problems (including a mild confabulation tendency) emerged during the first pregnancy, and after delivery a clinical neuropsychological examination showed memory impairment. She was not depressed, and a control examination six months later (before the second pregnancy) showed improvement. After the second delivery, clinical neuropsychological examinations at the ages of 36, 38, 40, 41, and 44 showed memory and attention deficits, with intrusions noted in two examinations. MRI was normal at the age of 29 , one year after the first delivery and before the second pregnancy. After the second delivery, MRIs at the ages of 38, 42, 43, and 47 showed mild cerebellar vermis atrophy. Peripheral neuropathy manifested during the first pregnancy and is treated with lamotrigine and nortriptyline.

\subsubsection{Comorbidities}

Eight years before the first WE, the patient was diagnosed with systemic lupus erythematosus (SLE), which is treated with prednisolone (2.5-5 mg/day) and hydroxychloroquine.

\subsubsection{Prior psychiatric treatment}

At the age of 39, eight years after the second WE, the patient was diagnosed with moderate major depression at the psychiatric outpatient clinic of Turku University Hospital. Antidepressant medication (escitalopram $20 \mathrm{mg} / \mathrm{day}$, citalopram $40 \mathrm{mg} /$ day) was of no clear benefit.

\subsubsection{Course and outcome}

Before being diagnosed with SLE, the patient had excellent grades at school. Chronic fatigue forced her to interrupt high school and she became an artisan, but she has worked as a factory worker. Following the second delivery, the patient has been mostly on sick leave or unemployed and on a part-time disability pension for the last five years. She has been treated by GN for the last six years. Bupropion ( $300 \mathrm{mg} / \mathrm{day}$ ), venlafaxine (150 mg/day), and duloxetine ( $60 \mathrm{mg} /$ day) medications were tried, but they were discontinued because of side-effects. Currently, at the age of 48 , the patient has mild mood symptoms, and she is unable to work even part-time due to the continuing memory impairment.

\subsection{Patient 2}

This female patient was referred to GN by her occupational health physician for a psychiatric assessment because of moderate major depression at the ages of 54 and 55.

\subsubsection{WE and memory impairment}

The patient was diagnosed with hypogammaglobulinemia at the age of 42 . She was treated with cortisone and antibiotics for pyelonephritis, pneumonia, and severe urticaria. A CT examination showed frontal atrophy. There was weight loss and WE manifestations (Table 1), and she has since had memory problems. Clinical neuropsychological examinations at the ages of 50,53, and 55 showed deficits in memory (with intrusions), attention, visuoconstructive abilities, and executive functions. MRIs at the ages of 43 and 55 showed mild symmetrical atrophy of the superior frontal lobes and a small arachnoid cyst in the cerebellum. The second MRI was a 3T examination taken at the time of PET.

\subsubsection{Prior psychiatric treatment}

The patient was treated for mood problems and anxiety at the ages of 39,41 , and 43 .

\subsubsection{Course and outcome}

Antidepressant medication (venlafaxine $150 \mathrm{mg} /$ day) reduced the psychiatric symptoms, but the memory impairment persisted. The patient has a college degree and is on a partial disability pension.

Table 1

Causes and manifestations of non-alcoholic Wernicke's encephalopathy in three psychiatric patients with Korsakoff syndrome.

\begin{tabular}{|c|c|c|c|c|c|c|c|c|}
\hline \multirow{2}{*}{$\begin{array}{l}\text { Patient } \\
\text { No. }\end{array}$} & \multirow{2}{*}{$\begin{array}{l}\text { Age }^{\mathrm{a}} \\
\text { (years) }\end{array}$} & \multirow{2}{*}{$\begin{array}{l}\text { Cause of } \\
\text { Wernicke's } \\
\text { encephalopathy }\end{array}$} & \multicolumn{3}{|c|}{ Nutritional deficiency } & \multicolumn{3}{|c|}{ Symptoms and signs of Wernicke's encephalopathy } \\
\hline & & & Duration & $\begin{array}{l}\text { Weight loss } \\
(\mathrm{kg})\end{array}$ & $\begin{array}{l}\text { Lowest } \\
\text { BMI }\end{array}$ & Ocular & Unsteadiness/ataxia & $\begin{array}{l}\text { Altered mental state or mild memory } \\
\text { impairment }\end{array}$ \\
\hline $1^{\mathrm{b}}$ & 28 & $\begin{array}{l}\text { Hyperemesis } \\
\text { gravidarum }\end{array}$ & 8 months & $\mathrm{N} / \mathrm{A}$ & $\mathrm{N} / \mathrm{A}$ & Impaired vision $^{\mathrm{c}}$ & Unsteadiness & Mild confusion, memory impairment \\
\hline $1^{\mathrm{b}}$ & 30 & $\begin{array}{l}\text { Hyperemesis } \\
\text { gravidarum }\end{array}$ & 8 months & $\mathrm{N} / \mathrm{A}$ & $\mathrm{N} / \mathrm{A}$ & - & Unsteadiness & Mild confusion \\
\hline 2 & 42 & Vomiting, infection & 2 months & 10 & $\mathrm{~N} / \mathrm{A}$ & Diplopia $^{\mathrm{c}}$, exophoria ${ }^{\mathrm{c}}$, impaired vision ${ }^{\mathrm{c}}$ & - & Mild confusion \\
\hline 3 & 37 & Diarrhea \& vomiting & 6 months & $5^{c}$ & $15.6^{\mathrm{c}}$ & $\begin{array}{l}\text { Anisocoria }{ }^{\mathrm{c}} \text {, impaired vision }{ }^{\mathrm{c}} \\
\text { photosensitivity }^{\mathrm{c}}\end{array}$ & $\begin{array}{l}\text { Unsteadiness, } \\
\text { clumsiness }^{\mathrm{c}}\end{array}$ & Memory impairment ${ }^{\mathrm{c}}$ \\
\hline
\end{tabular}

$\mathrm{N} / \mathrm{A}=$ Not available.

a Age at the time of Wernicke's encephalopathy.

b Patient 1 had two episodes of WE.

c Information from hospital records. 


\subsection{Patient 3}

This female patient has been treated by GN since the age of 43 years, when she had already been on treatment at an outpatient psychiatric clinic.

\subsubsection{WE and memory impairment}

The patient had gastroenteritis after her second delivery at the age of 37. For the next six months, she had daily morning nausea and vomiting, her weight dropped, and she developed typical WE symptoms (Table 1). MRI was normal, as well as MRIs at the ages of 42 and 44. She has had memory problems (including a mild confabulation tendency) since the WE episode. In her early twenties, she learned many plant names in Finnish and Latin. In her gardening job, she has mainly used the Latin names. After WE, she only remembers those Latin names. In addition, she remembers poorly events from a period of two years before the WE. At the age of 38, a clinical neuropsychological examination found impairment of attention and memory. Examinations at the ages of 42 and 43 showed some improvement. Seventeen years before the WE, she had had diarrhea for six months and her weight dropped, but there were no WE manifestations.

\subsubsection{Prior psychiatric treatment}

A few months after the WE, the patient was referred for a psychiatric evaluation to the outpatient psychiatric clinic and was diagnosed with neurasthenia and moderate major depression. She was treated with citalopram $20 \mathrm{mg} /$ day, which reduced anxiety but did not affect the memory problem.

\subsubsection{Course and outcome}

Currently, at the age of 45 , the patient uses citalopram $20 \mathrm{mg} / \mathrm{day}$, clonazepam $0.5 \mathrm{mg} / \mathrm{day}$, and gabapentin $600 \mathrm{mg} /$ day medications, and she has mild mood symptoms. She has unsteadiness and intermittent anisocoria, and the memory impairment has persisted.

\section{Methods}

All patients underwent a neuropsychological examination between December 2014 and February 2015. Results at least 1.5 SDs lower than the mean of normative values were considered abnormal. Patients 1 and 3 underwent a 3T MRI examination with DTI using a previously described protocol [21]. We examined the corpus callosum (genu, body, and splenium), the superior and inferior cingulum, the uncinate fasciculus (UF), the superior longitudinal fasciculus, the arcuate fasciculus, the inferior fronto-occipital fasciculus, the inferior longitudinal fasciculus (ILF), the projection tracts through corona radiata, the prefrontal projection fibers, and the projection tracts through mesencephalon. Since only the descending fornix is damaged in alcoholic WE [22], the entire fornix and the descending fornix were examined separately. FAvalues at least 2 SDs lower than the mean of normal controls were considered abnormal. Patients 1 and 3 were examined twice, in 2010/2015 and 2013/2014, respectively, and their results remained unchanged. All patients were examined by [18F]-fluorodeoxyglucose (FDG) PET examination at the Turku University Hospital between 2012 and 2014. Patients 1 and 3 were examined twice, in 2012/2014 and 2013/2014 respectively.

\section{Results}

\subsection{Neuropsychological examination}

All patients had abnormal results in verbal immediate and delayed recall, and verbal recognition (Table 2). Patient 1 had impaired visual delayed recall, and patient 2 had impaired visual immediate and delayed recall. Visual and verbal working memory was normal. In the Hopkins Verbal Learning Test - Revised, Patients 1 and 3 had five intrusions,

\section{Table 2}

Results of neuropsychological tests of memory function for three patients with nonalcoholic Korsakoff syndrome.

\begin{tabular}{|c|c|c|c|c|}
\hline & Test & Patient 1 & Patient 2 & Patient 3 \\
\hline Age $^{a}$ & & 46 & 55 & 43 \\
\hline \multicolumn{5}{|l|}{ Working memory } \\
\hline Verbal & & -1 & 0 & -1.33 \\
\hline Visual & & -1 & 0 & -0.67 \\
\hline \multicolumn{5}{|l|}{ Episodic memory } \\
\hline \multicolumn{5}{|l|}{ Immediate recall } \\
\hline \multirow[t]{2}{*}{ Verbal } & HVLT-R ${ }^{\mathrm{b}}$ & -1.64 & -1.08 & -1.80 \\
\hline & WMS-III ${ }^{\mathrm{C}}$ & -1.67 & -1.67 & -0.33 \\
\hline Visual & BVMT-R $^{\mathrm{d}}$ & -1.28 & -1.75 & 0.20 \\
\hline \multicolumn{5}{|l|}{ Delayed recall } \\
\hline \multirow[t]{2}{*}{ Verbal } & HVLT-R ${ }^{\mathrm{e}}$ & -3.46 & -3.28 & -2.02 \\
\hline & WMS-III ${ }^{\mathrm{f}}$ & -2.33 & -2 & -0.67 \\
\hline Visual & BVMT-R ${ }^{g}$ & -1.75 & -2.33 & 0.31 \\
\hline \multirow[t]{2}{*}{ Verbal recognition } & HVLT-R ${ }^{\mathrm{h}}$ & -1.67 & -4.08 & -2.48 \\
\hline & WMS-III ${ }^{\mathrm{i}}$ & -2 & 0 & -0.67 \\
\hline
\end{tabular}

Test results are $z$-scores from the distribution of normative values. Values $\leq-1.5$ are in bold.

a Age (years) at the neuropsychological examination.

b Hopkins Verbal Learning Test - Revised (HVLT-R), sum of the first three learning trials.

c Wechsler Memory Scale (WMS-III), logical memory I.

d Brief Visuospatial Memory Test - Revised (BVMT-R), sum of the first three learning trials.

e HVLT-R, delayed free recall trial (trial 4).

f WMS-III, logical memory II.

g BVMT-R, delayed free recall trial (trial 4).

h HVLT-R, recognition trial.

${ }^{\mathrm{i}}$ WMS-III, logical memory recognition score +24 (presumed perfect Verbal Paired Associates recognition). According to Lezak, Howieson, Bigler, and Tranel, Neuropsychological assessment, 5th edition (2012), page 527.

and Patient 2 had no intrusions. In the logical memory test (Wechsler Memory Scale - III), Patient 1 had 10 intrusions, patient 2 had 12 intrusions and Patient 3 had 16 intrusions. In the other neuropsychological tests, including tests of executive functions, all results were normal (Table 3).

\subsection{DTI (Fig. 1)}

We found abnormal FA-values in both patients examined: in the UF (Patient 3, both sides), the ILF (Patient 1, both sides), and the corona radiata (Patient 1 left side, Patient 3 both sides).

Table 3

Results of neuropsychological tests other than memory for three patients with non-alcoholic Korsakoff syndrome.

\begin{tabular}{lccc}
\hline & Patient 1 & Patient 2 & Patient 3 \\
\hline Age $^{\mathrm{a}}$ (years) & 46 & 55 & 43 \\
General attention $^{\mathrm{b}}$ & -0.25 & 0 & -0.84 \\
Divided attention $^{\mathrm{c}}$ & 0.84 & 1.28 & 0.52 \\
Psychomotor speed $^{\mathrm{d}}$ & 0 & 0 & -1 \\
Verbal skill $^{\mathrm{e}}$ & -0.67 & -0.67 & -1 \\
Executive functions $^{\mathrm{Planning} \& \text { foresight }^{\mathrm{f}}}$ & & & \\
Set shifting $^{\mathrm{g}}$ & 0.81 & -1.23 & 0.10 \\
Task switching $^{\mathrm{h}}$ & 0.74 & -0.28 & 0.33 \\
Verbal fluency $^{\mathrm{i}}$ & 0.67 & 1.96 & 1.04 \\
Composite score $^{\mathrm{j}}$ & 0.20 & 3.09 & 0.31 \\
\hline
\end{tabular}

Test results are $z$-scores from the distribution of normative values.

a Age at the neuropsychological examination.

b Trail Making Test A.

c Trail Making Test B.

d Digit symbol subtest of the Wechsler Adult Intelligence Scale-III.

e Vocabulary subtest of the Wechsler Adult Intelligence Scale-III.

f NAB Mazes test.

g Wisconsin Card Sorting test.

h Trail Making Test B score -Trail Making Test A score.

The category fluency test (animals) and the word fluency test (words starting with the letter "s").

j Average of ${ }^{\mathrm{f}, \mathrm{g}, \mathrm{h}}$, and ${ }^{\mathrm{i}}$ 


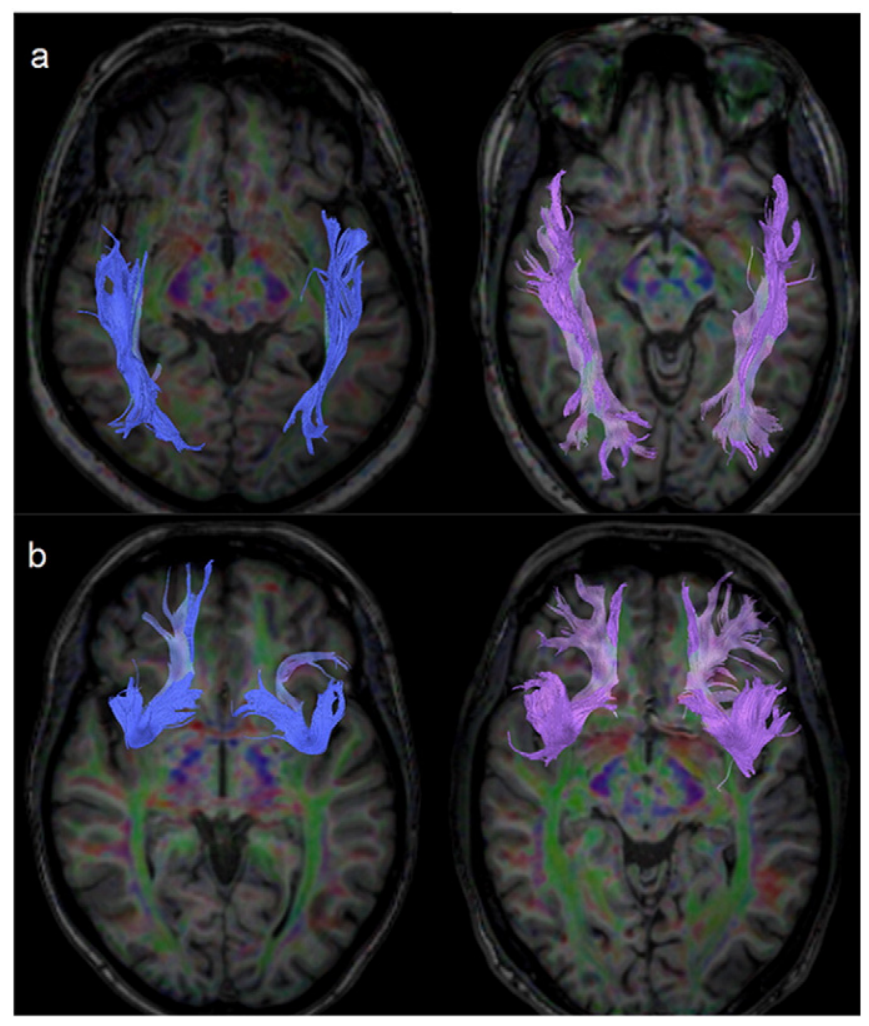

Fig. 1. Reduction of fibers and volumes in the tractograms of the inferior longitudinal fasciculus of patient 1 (a) and in the tractograms of the uncinate fasciculus of patient 3 (b) obtained at threshold FA 0.15 and angle 27 degrees (blue); tractograms of a normal control obtained at the same thresholds are shown on the right as violet.

\subsection{PET (Fig. 2)}

Patient 1 had mild hypometabolism in the lateral temporal cortex bilaterally in both examinations. In a clinical semiquantitative comparison with normal controls, the left temporal area showed a radioligand uptake of -1.9 SDs in 2012 and - 1.4 SDs in 2014, and the right temporal area an uptake of -1.6 SDs in 2012 and -1.1 SDs in 2014. Patient 2 had two normal PET examinations. Patient 3 had mild hypometabolism in the superior frontal lobes.

\section{Discussion}

We have described three non-alcoholic psychiatric patients with long-term memory difficulties likely related to previously undiagnosed WE. Neuropsychological examination showed memory impairment. DTI showed persistently decreased FA-values in two patients. PET showed mild hypometabolism in two patients.

In all nine previously reported cases of non-alcoholic KS where delayed memory was tested, it was found impaired [12-19]. Immediate memory was impaired in five of eight tested cases [13-16,20], in one case it was reported as unaffected but test results appear to indicate impairment [19], in one case impairment receded during follow-up [12], and in one case immediate memory was normal [17]. Recognition was impaired in all three tested cases $[12,14,19]$. Working memory was examined in five cases; in four cases, it was normal $[13,14,19,20]$, whereas in one case impairment receded during follow-up [16]. Intrusions (provoked confabulations) in neuropsychological testing indicate organic brain damage, including alcoholic KS [23-25]. In two previously reported cases of non-alcoholic KS intrusions were reported [15,19], whereas in another case there were no intrusions [14]. In alcoholic KS executive functions are impaired [26]. Executive functions were tested in seven previously reported cases of non-alcoholic KS; in five cases they were impaired $[12,13,15,16,19]$, and in one case they were intact [14]. One study reported impairment, but test results can be interpreted as normal [20]. Neuropsychological testing of our patients showed impairment confined to immediate and delayed episodic memory with intrusions. Thus, the results of memory tests in our patients strongly support the diagnosis of KS. Normal results in testing of executive functions in our patients suggest that impairment of executive functions may be more common in alcoholic compared to non-alcoholic KS, although the small number of patients in our study does not allow firm conclusions to be made. Preservation of executive functions may help patients partially adjust to the memory impairment and lead to underdiagnosis of non-alcoholic KS. Remote memory impairment has been previously documented neuropsychologically in two non-alcoholic KS patients [13,14], whereas in one case impairment receded during follow-up [12] and in another improved [17]. We did not test remote
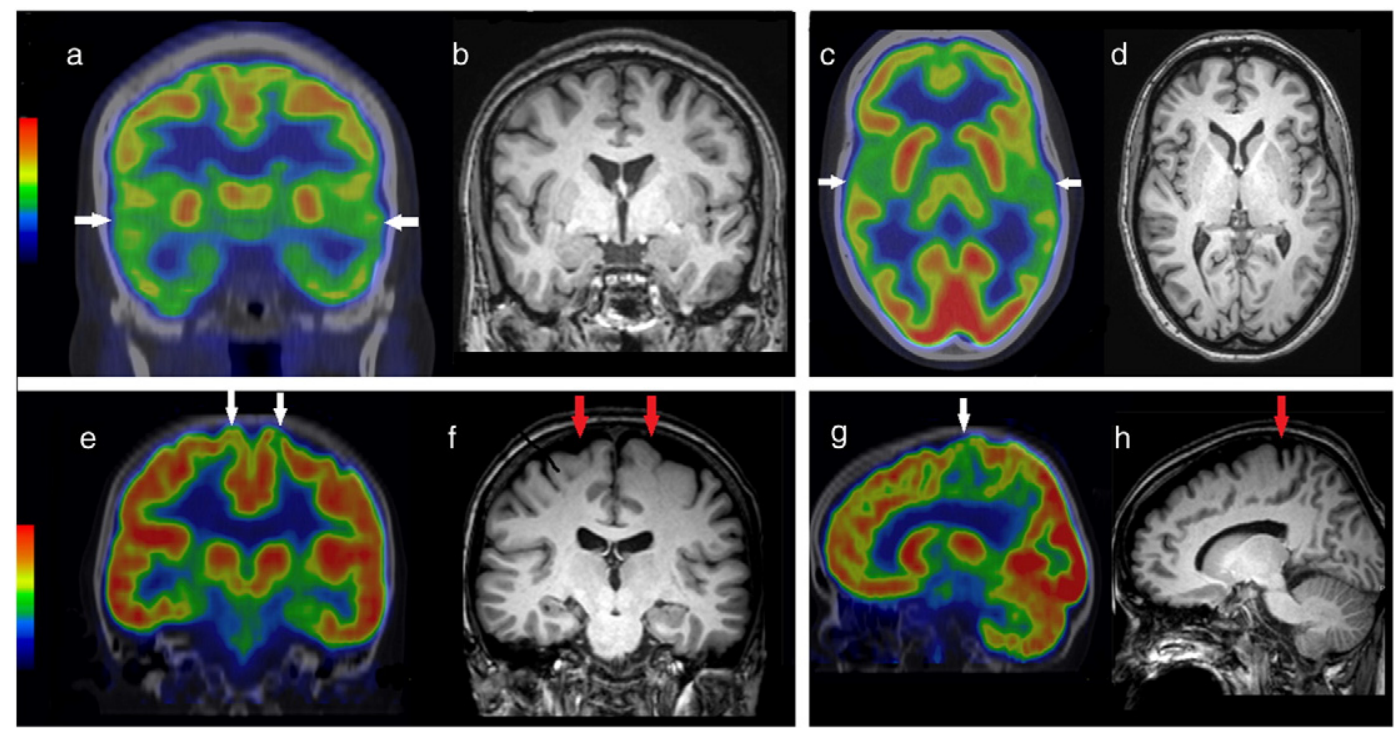

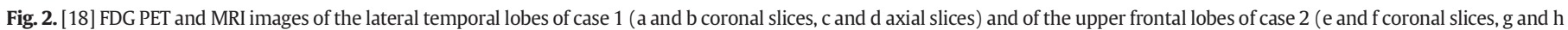
sagittal slices). White and red arrows show areas of hypometabolism and atrophy, respectively. 
memory. Clinically, Patient 3 has retrograde semantic memory impairment compatible with the multiple trace theory, where rehearsal and reactivation protect memories [27]. This patient has also retrograde autobiographical memory impairment with a temporal gradient.

Patient 3 had a normal MRI during WE. The diagnostic sensitivity of MRI in alcoholic WE is only 53\% [28]. In the review by Galvin et [5], conventional MRI was positive for non-alcoholic WE in $99 \%$ of the cases belonging to clinical series. However, a positive MRI finding was an essential reason for diagnosis, which suggests a selection bias. In contrast, in a recent study of non-alcoholic WE serum thiamine was measured in most patients, and reliance on MRI for diagnosis was probably less pronounced [7]. In this study, only three out of ten patients had WE findings in MRI.

The medical records of our patients do not mention that the diagnosis of WE was considered at the time of occurrence. Our results support the need for a high index of suspicion for non-alcoholic WE in a broad range of clinical situations, as previously stressed [2-5,7]. Repeated episodes of subclinical alcoholic WE may cause KS $[29,30]$. Patients 1 and 3 had two periods of probable nutritional deficiency. Only in Patient 1 both episodes were accompanied by WE symptoms, and the memory impairment improved in between. During WE, coexisting deficiencies of other micronutrients might have exacerbated the deleterious effect of thiamine deficiency in our patients [31].

In all five previously reported cases of neuropsychologically documented non-alcoholic KS also studied with MRI, there were no atrophy findings [12,13,15,17,19]. However, MB atrophy [32-34], thalamic atrophy [35], and vermis atrophy [36] have been reported in studies that mention memory impairment after non-alcoholic WE. In our patients, there was no marked atrophy in MRI. Patient 1 had mild cerebellar vermis atrophy that probably emerged during or after the second WE episode. The memory impairment improved between the two WE episodes, but since the second episode, the impairment has persisted. Vermis atrophy developing only after the second non-alcoholic WE episode has been recently reported [37], but there is no information on the cognitive outcome of this patient. Patient 3 had mild symmetrical atrophy of the superior prefrontal cortex. Frontal atrophy is common in alcoholic KS [38]. Voxel-based MRI morphometry has shown graded volume deficits in the MBs, medial thalamus, left insula, and genu of the corpus callosum of KS and non-KS alcoholic patients in one study [39], whereas in another study parahippocampal/hippocampal atrophy was specific to KS and thalamic atrophy and third ventricle enlargement were more severe in patients with KS than in cognitively normal alcoholic patients [40].

There are no previous DTI studies in non-alcoholic KS. In a previous comparison of alcoholic KS patients and uncomplicated alcoholics, DTI revealed damage in the corpus callosum and anterior corona radiata in KS [41]. In another recent DTI study, the fornix was damaged in alcoholic KS but also in alcoholics without KS [42]. Two of our patients were examined with DTI, and reduced FA-values were found in the corona radiata, the UF, and the ILF. Patient 3 , who has clinically retrograde amnesia, had clearly decreased UF FA-values. It has been suggested that disconnection between the frontal and temporal lobe (which the UF connects) can cause retrograde amnesia [43]. UF and ILF damage is associated with memory impairment [44-46]. More studies are needed in order to further evaluate whether persistent microstructural white matter changes, as assessed by DTI, can be used a s a biomarker of non-alcoholic KS.

In non-alcoholic KS, hypometabolism has been shown in the thalami and the frontal, temporal, parietal, and occipital lobes [15,16,18]. Patient 1 had mild hypometabolism in the lateral temporal cortex, an area important in anterograde semantic [47] and episodic [48] memory, and retrograde memory [49]. Patient 3 had mild hypometabolism in the superior frontal lobes.

Two of our patients had other chronic consequences of WE. Chronic peripheral neuropathy (Patient 1 ) and unsteadiness (patient 3 ) are not uncommon after WE [22]. Intermittent anisocoria (Patient 3 ) has been described in an early report of WE [50].
The diagnosis of KS can be missed because clinicians often expect atrophy of the mammillary bodies (MBs) in MRI and confabulations. Confabulation tendency usually subsides after the early phase [1]. Given the dearth of non-alcoholic KS reports, clinicians may rely on studies of alcoholic KS, which predominantly have described severe cases without psychiatric disease. However, the range of memory impairment in alcoholic KS is wide [22], and more than half of patients with alcoholic KS have a psychiatric diagnosis and use psychotropic medication [51]. A diagnosis of non-alcoholic KS is not routinely considered in patients with memory impairment and, as in our patients, memory complaints can be erroneously seen as a cognitive symptom of a psychiatric disorder.

Our results support the notion that KS patients with undiagnosed WE may be encountered by psychiatrists [1]. We speculate that non-alcoholic KS after undiagnosed WE may cause development or deterioration of psychiatric symptoms. These patients face bewildering vocational and everyday life problems caused by the memory impairment. Extensive cognitive coping efforts may lead to exhaustion, distress, compromise of psychic resources, and mood symptoms. Brain damage of intermediate severity is more probable to cause emotional disturbance compared to mild or very severe brain damage [52].

Our study has several limitations. We did not test remote memory and for spontaneous confabulations. PET was interpreted clinically and to avoid false positive results we used a very low threshold FA-value in DTI, which reduced sensitivity. Comorbidity is an important concern. SLE in Patient 1 has had a stable course with no flares. Memory impairment in SLE is associated with cerebral atrophy or vascular lesions [53], or hippocampal atrophy [54]. Mild cognitive deficits can occur with normal MRI, but memory is not disproportionally affected [55]. Therefore, it is very unlikely that SLE has caused the memory problem. Psychiatric disease can cause cognitive impairment. Anterograde episodic memory may be impaired in major depression, but cognitive functions are usually broadly affected [56]. Intrusions in memory testing may occur in depression too, but they are associated with anosognosia for the memory deficit [57]. In a study of slightly younger subjects, psychiatric patients produced a mean of 0.47 and controls a mean of 0.18 intrusions in the Hopkins Verbal Learning Test - Revised, the difference was not statistically significant [58]. DTI changes have been described in mood disorders, but according to a recent meta-analysis they are restricted to the corpus callosum and the cingulum [59]. Depression is associated with brain hypometabolism but not in the temporal lobes or the superior frontal lobes [60]. The memory problems of Patients 1 and 3 began at the time of WE; psychiatric symptoms developed later. The memory impairments of Patients 2 and 3 have persisted, although psychiatric treatment has been otherwise beneficial. Our patients are unable to work because of memory impairment despite appropriate psychiatric treatment.

Our study has also strengths. The patients have been followed for up to six years and were last assessed 7-18 years after WE. This long follow-up period increases confidence in the KS diagnosis. Findings from the previous clinical neuropsychological examinations also support the diagnosis of KS. Our neuropsychological examination and the DTI were the same for all patients.

Our results suggest that non-alcoholic KS is underdiagnosed in psychiatric patients with a history of malnutrition, and expand the diagnostic spectrum to the recognition of KS among psychiatric patients with memory impairment of intermediate severity. Diagnosing somatic disease is essential in psychiatric care. Non-alcoholic KS should be considered for all patients with chronic, non-progressive memory impairment. Studying these patients in sufficient numbers could provide a better understanding of KS and memory function.

\section{Acknowledgements}

We thank Terhi Tuokkola, MD, for discussions on the results of PET imaging. This research did not receive any specific grant from funding agencies in the public, commercial, or not-for-profit sectors. 


\section{References}

[1] M.D. Kopelman, A.D. Thomson, I. Guerrini, E.J. Marshall, The Korsakoff syndrome: clinical aspects, psychology and treatment. Alcohol Alcohol. 44 (2009) 148-154, http://dx.doi.org/10.1093/alcalc/agn118.

[2] E. Isenberg-Grzeda, H.E. Kutner, S.E. Nicolson, Wernicke-Korsakoff-syndrome: under-recognized and under-treated, Psychosomatics 53 (2012) 507-516, http://dx.doi.org/10.1016/j.psym.2012.04.008.

[3] G. Sechi, A. Serra, Wernicke's encephalopathy: new clinical settings and recent advances in diagnosis and management, Lancet Neurol. 6 (2007) 442-455, http://dx.doi.org/10.1016/S1474-4422(07)70104-7.

[4] M.E. Lough, Wernicke's encephalopathy: expanding the diagnostic toolbox. Neuropsychol. Rev. 22 (2012) 181-194, http://dx.doi.org/10.1007/s11065-012-9200-7.

[5] R. Galvin, G. Bråthen, A. Ivashynka, M. Hillbom, R. Tanasescu, M.A. Leone, EFNS guidelines for diagnosis, therapy and prevention of Wernicke encephalopathy, Eur. J. Neurol. 17 (2010) 1408-1418, http://dx.doi.org/10.1111/j.1468-1331.2010.03153.x.

[6] D. Caine, G.M. Halliday, J.J. Kril, C.G. Harper, Operational criteria for the classification of chronic alcoholics: identification of Wernicke's encephalopathy. J. Neurol. Neurosurg. Psychiatry 62 (1997) 51-60, http://dx.doi.org/10.1136/jnnp.62.1.51.

[7] E. Isenberg-Grzeda, Y. Alici, V. Hatzoglou, C. Nelson, W. Breitbart, Nonalcoholic thiamine-related encephalopathy (Wernicke-Korsakoff Syndrome) among inpatients with cancer: a series of 18 Cases, Psychosomatics 57 (2016) 71-81, http://dx.doi.org/10.1016/j.psym.2015.10.001

[8] J. Homewood, N.W. Bond, Thiamin deficiency and Korsakoff's syndrome: failure to find memory impairments following nonalcoholic Wernicke's encephalopathy. Alcohol 19 (1999) 75-84, http://dx.doi.org/10.1016/S0741-8329(99)00027-0.

[9] A.D. Thomson, I. Guerrini, E.J. Marshall, The evolution and treatment of Korsakoff's syndrome: out of sight, out of mind? Neuropsychol. Rev. 22 (2012) 81-92, http://dx.doi.org/10.1007/s11065-012-9196-z.

[10] G. Freund, Chronic central nervous system toxicity of alcohol, Annu. Rev. Pharmacol. 13 (1973) 217-227, http://dx.doi.org/10.1146/annurev.pa.13.040173.001245.

[11] S.J. Scalzo, S.C. Bowden, M.L. Ambrose, G. Whelan, M.J. Cook, Wernicke-Korsakoff syndrome not related to alcohol use: a systematic review, J. Neurol. Neurosurg. Psychiatry 86 (2015) 1362-1368, http://dx.doi.org/10.1136/jnnp-2014-309598.

[12] W.W. Beatty, R.C. Bailly, L. Fisher, Korsakoff-like amnestic syndrome in a patient with anorexia and vomiting, Int. J. Clin. Neuropsychol. 11 (1989) 55-65.

[13] A.J. Parkin, J. Blunden, J.E. Rees, N.M. Hunkin, Wernicke-Korsakoff syndrome of nonalcoholic origin, Brain Cogn. 15 (1991) 69-82.

[14] J.T. Becker, J.M.R. Furman, M. Panisset, C. Smith, Characteristics of the memory loss of a patient with Wernicke-Korsakoff's syndrome without alcoholism, Neuropsychologia 28 (1990) 171-179, http://dx.doi.org/10.1016/0028-3932(90)90099-A.

[15] S. Deb, R. Law-Min, D. Fearnley, Wernicke-Korsakoff syndrome following small bowel obstruction, Behav. Neurol. 13 (2002) 89-94.

[16] F. Giovannelli, B. Basagni, L. Potenza, V. Foschi, A. De Tanti, Long-term cognitive sequelae in a case of Wernicke's encephalopathy after allogeneic stem cell transplantation, Neurocase 22 (2016) 187-190, http://dx.doi.org/10.1080/13554794.2015.1109666.

[17] M. Caulo, J. Van Hecke, L. Toma, A. Ferretti, A. Tartaro, C. Colosimo, G.L. Romani, A. Uncini, Functional MRI study of diencephalic amnesia in Wernicke-Korsakoff syndrome. Brain 128 (2005) 1584-1594, http://dx.doi.org/10.1093/brain/awh496.

[18] T. Shimomura, E. Mori, N. Hirono, T. Imamura, H. Yamashita, Development of Wernicke-Korsakoff syndrome after long intervals following gastrectomy, Arch. Neurol. 55 (1998) 1242-1245, http://dx.doi.org/10.1001/archneur.55.9.1242.

[19] E. Fertl, P. Schnider, C. Müller, E. Auff, Persistent amnesic syndrome as long-term outcome of cognitive function after Whipple's disease, Eur. J. Neurol. 4 (1997) 613-617, http://dx.doi.org/10.1111/j.1468-1331.1997.tb00414.x

[20] F. Caso, A. Fiorino, M. Falautano, L. Leocani, V. Martinelli, F. Minicucci, A. Falini, G. Comi, G. Magnani, Treatment of Wernicke's encephalopathy with high dose of thiamine in a patient with pyloric sub-stenosis: description of a case, Neurol. Sci. 31 (2010) 859-861, http://dx.doi.org/10.1007/s10072-010-0253-1.

[21] T. Kurki, L. Himanen, E. Vuorinen, A. Myllyniemi, A.-R. Saarenketo, T. Kauko, N. Brandstack, O. Tenovuo, Diffusion tensor tractography-based analysis of the cingulum: clinical utility and findings in traumatic brain injury with chronic sequels, Neuroradiology 56 (2014) 833-841, http://dx.doi.org/10.1007/s00234-014-1410-7.

[22] M. Victor, R.D. Adams, G.H. Collins, The Wernicke-Korsakoff Syndrome and Related Neurologic Disorders Due to Alcoholism and Malnutrition (Contemporary Neurology), 2nd ed. F. A. Davies Company, Philadelphia, PA, 1989

[23] N. Butters, E. Granholm, D.P. Salmon, I. Grant, J. Wolfe, Episodic and semantic memory: a comparison of amnesic and demented patients, J. Clin. Exp. Neuropsychol. 9 (1987) 479-497, http://dx.doi.org/10.1080/01688638708410764.

[24] M.D. Kopelman, Two types of confabulation, J. Neurol. Neurosurg. Psychiatry 50 (1987) 1482-1487, http://dx.doi.org/10.1136/jnnp.50.11.1482.

[25] A. Schnider, The confabulating mind, How the Brain Creates Reality, Oxford University Press, 2008.

[26] C.L. Dirksen, J.A. Howard, A. Cronin-Golomb, M. Oscar-Berman, Patterns of prefrontal dysfunction in alcoholics with and without Korsakoff's syndrome, patients with Parkinson's disease, and patients with rupture and repair of the anterior communicating artery, Neuropsychiatr. Dis. Treat. 2 (2006) 327-339, http://dx.doi.org/10.2147/nedt.2006.2.3.327.

[27] M. Moscovitch, L. Nadel, G. Winocur, A. Gilboa, R.S. Rosenbaum, The cognitive neuroscience of remote episodic, semantic and spatial memory, Curr. Opin. Neurobiol. 16 (2006) 179-190, http://dx.doi.org/10.1016/j.conb.2006.03.013.

[28] E. Antunez, R. Estruch, C. Cardenal, J.M. Nicolas, J. Fernandez-Sola, A. UrbanoMarquez, Usefulness of CT and MR imaging in the diagnosis of acute Wernicke's encephalopathy, AJR Am. J. Roentgenol. 171 (1998) 1131-1137, http://dx.doi.org/10.2214/ajr.171.4.9763009.
[29] W.A. Lishman, Cerebral disorder in alcoholism, Brain 104 (1981) 1-20, http://dx.doi.org/10.1093/brain/104.1.1.

[30] C. Harper, The incidence of Wernicke's encephalopathy in Australia-a neuropathological study of 131 cases, J. Neurol. Neurosurg. Psychiatry 46 (1983) 593-598, http://dx.doi.org/10.1136/jnnp.46.7.593.

[31] G. Sechi, E. Sechi, C. Fois, N. Kumar, Advances in clinical determinants and neurological manifestations of B vitamin deficiency in adults, Nutr. Rev. 74 (2016) 281-300, http://dx.doi.org/10.1093/nutrit/nuv107.

[32] J. Gascón-Bayarri, J. Campdelacreu, M.C. García-Carreira, J. Estela, S. MartínezYélamos, A. Palasí, T. Delgado, R. Reñé, [Wernicke's encephalopathy in nonalcoholic patients: a series of 8 cases]. Neurologia 26 (2011) 540-547, http://dx.doi.org/10.1016/j.nrl.2011.03.001.

[33] M. Nolli, A. Barbieri, C. Pinna, A. Pasetto, F. Nicosia, Wernicke's encephalopathy in a malnourished surgical patient: clinical features and magnetic resonance imaging. Acta Anaesthesiol. Scand. 49 (2005) 1566-1570, http://dx.doi.org/10.1111/j.1399-6576.2005.00879.x.

[34] P. D'Aprile, M.A. Gentile, A. Carella, Enhanced MR in the acute phase of Wernicke encephalopathy. AJNR Am. J. Neuroradiol. 15 (1994) 591-593.

[35] A. Doss, D. Mahad, C.A.J. Romanowski, Wernicke encephalopathy: unusual findings in nonalcoholic patients, J. Comput. Assist. Tomogr. 27 (2003) 235-240.

[36] S.H. Park, M. Kim, D.L. Na, B.S. Jeon, Magnetic resonance reflects the pathological evolution of Wernicke encephalopathy. J. Neuroimaging 11 (2001) 406-411.

[37] S. Lamdhade, A. Almulla, R. Alroughani, Recurrent Wernicke's encephalopathy in a 16-year-old girl with atypical clinical and radiological features, Case Rep. Neurol. Med. 2014 (2014) 1-6, http://dx.doi.org/10.1155/2014/582482.

[38] A.-L. Pitel, A.-M. Aupée, G. Chételat, F. Mézenge, H. Beaunieux, V. de la Sayette, F. Viader, J.-C. Baron, F. Eustache, B. Desgranges, Morphological and glucose metabolism abnormalities in alcoholic Korsakoff's syndrome: group comparisons and individual analyses, PLoS One 4 (2009), e7748 http://dx.doi.org/10.1371/journal.pone.0007748.

[39] A.-L. Pitel, G. Chételat, A.P. Le Berre, B. Desgranges, F. Eustache, H. Beaunieux, Macrostructural abnormalities in Korsakoff syndrome compared with uncomplicated alcoholism, Neurology 78 (2012) 1330-1333, http://dx.doi.org/10.1212/WNL.0b013e318251834e.

[40] T. Matsui, H. Sakurai, T. Toyama, A. Yoshimura, S. Matsushita, S. Higuchi, [Clinical application of neuroimaging to alcohol-related dementia], Nihon Arukoru Yakubutsu Igakkai Zasshi 47 (2012) 125-134.

[41] S. Segobin, L. Ritz, C. Lannuzel, C. Boudehent, F. Vabret, F. Eustache, H. Beaunieux, A.-L. Pitel, Integrity of white matter microstructure in alcoholics with and without Korsakoff's syndrome, Hum. Brain Mapp. 36 (2015) 2795-2808, http://dx.doi.org/10.1002/hbm.22808.

[42] L. Nahum, J.-M. Pignat, A. Bouzerda-Wahlen, D. Gabriel, M.C. Liverani, F. Lazeyras, R. Ptak, J. Richiardi, S. Haller, G. Thorens, D.F. Zullino, A.G. Guggisberg, A. Schnider, Neural correlate of anterograde amnesia in Wernicke-Korsakoff syndrome, Brain Topogr. 28 (2015) 760-770, http://dx.doi.org/10.1007/s10548-014-0391-5.

[43] H.J. Markowitsch, Thalamic mediodorsal nucleus and memory: a critical evaluation of studies in animals and man, Neurosci. Biobehav. Rev. 6 (1982) 351-380, http://dx.doi.org/10.1016/0149-7634(82)90046-X.

[44] K.H. Alm, T. Rolheiser, F.B. Mohamed, I.R. Olson, Fronto-temporal white matter connectivity predicts reversal learning errors, Front. Hum. Neurosci. 9 (2015) 343, http://dx.doi.org/10.3389/fnhum.2015.00343.

[45] I.R. Olson, R.J. Von Der Heide, K.H. Alm, G. Vyas, Development of the uncinate fasciculus: implications for theory and developmental disorders, Dev. Cogn. Neurosci. 14 (2015) 50-61, http://dx.doi.org/10.1016/j.dcn.2015.06.003.

[46] C.R. McDonald, K.M. Leyden, D.J. Hagler, N.E. Kucukboyaci, N. Kemmotsu, E.S. Tecoma, V.J. Iragui, White matter microstructure complements morphometry for predicting verbal memory in epilepsy, Cortex 58 (2014) 139-150, http://dx.doi.org/10.1016/j.cortex.2014.05.014.

[47] P. Fletcher, L. Tyler, Neural correlates of human memory, Nat. Neurosci. 5 (2002) 8-9, http://dx.doi.org/10.1038/nn0102-8.

[48] M.-C. Cheung, A.S. Chan, Memory impairment in humans after bilateral damage to lateral temporal neocortex, Neuroreport 14 (2003) 371-374, http://dx.doi.org/10.1097/01.wnr.0000057865.05120.f3.

[49] R. Insausti, J. Annese, D.G. Amaral, L.R. Squire, Human amnesia and the medial temporal lobe illuminated by neuropsychological and neurohistological findings for patient E.P. Proc. Natl. Acad. Sci. U. S. A. 110 (2013) E1953-E1962, http://dx.doi.org/10.1073/pnas.1306244110.

[50] J. Turner, Alcoholic insanity (Korsakow's polyneurilic psychosis): its symptomatology and pathology, J. Ment. Sci. 56 (1910) 25-63.

[51] I.J. Gerridzen, M.A. Goossensen, Patients with Korsakoff syndrome in nursing homes: characteristics, comorbidity, and use of psychotropic drugs, Int. Psychogeriatr. 26 (2013) 1-7, http://dx.doi.org/10.1017/S1041610213001543.

[52] M.D. Lezak, D.B. Howieson, E.D. Bigler, D. Tranel, Neuropsychological Assessment, Fifth edition Oxford University Press, 2012.

[53] H. Ainiala, P. Dastidar, J. Loukkola, T. Lehtimäki, M. Korpela, J. Peltola, A. Hietaharju, Cerebral MRI abnormalities and their association with neuropsychiatric manifestations in SLE: a population-based study, Scand. J. Rheumatol. 34 (2005) 376-382, http://dx.doi.org/10.1080/03009740510026643.

[54] A. Schnider, C. Bassetti, A. Schnider, K. Gutbrod, C. Ozdoba, Very severe amnesia with acute onset after isolated hippocampal damage due to systemic lupus erythematosus, J. Neurol. Neurosurg. Psychiatry 59 (1995) 644-646, http://dx.doi.org/10.1136/jnnp.59.6.644-a.

[55] E. Kozora, C.M. Filley, Cognitive dysfunction and white matter abnormalities in systemic lupus erythematosus, J. Int. Neuropsychol. Soc. 17 (2011) 385-392, http://dx.doi.org/10.1017/S1355617711000191. 
[56] G.L. Iverson, B.L. Brooks, S.A. Langenecker, A.H. Young, Identifying a cognitive impairment subgroup in adults with mood disorders, J. Affect. Disord. 132 (2011) 360-367, http://dx.doi.org/10.1016/j.jad.2011.03.001.

[57] G.D. Barba, V. Parlato, A. Iavarone, F. Boller, Anosognosia, intrusions and "frontal" functions in Alzheimer's disease and depression, Neuropsychologia 33 (1995) 247-259, http://dx.doi.org/10.1016/0028-3932(94)00091-3.

[58] T.E. Van Rheenen, S.L. Rossell, Investigation of the component processes involved in verbal declarative memory function in bipolar disorder: utility of the Hopkins
Verbal Learning Test-Revised, J. Int. Neuropsychol. Soc. 20 (2014) 727-735, http://dx.doi.org/10.1017/S1355617714000484.

[59] T. Wise, J. Radua, G. Nortje, A.J. Cleare, A.H. Young, D. Arnone, Voxel-based meta-analytical evidence of structural disconnectivity in major depression and bipolar disorder Biol. Psychiatry 79 (2016) 293-302, http://dx.doi.org/10.1016/j.biopsych.2015.03.004.

[60] L. Su, Y. Cai, Y. Xu, A. Dutt, S. Shi, E. Bramon, Cerebral metabolism in major depressive disorder: a voxel-based meta-analysis of positron emission tomography studies, BMC Psychiatry 14 (2014) 321, http://dx.doi.org/10.1186/s12888-014-0321-9. 